\title{
Strong convergence theorems for common zeros of a family of accretive operators
}

\author{
Chunyan Huang ${ }^{1}$ and Xiaoyan $\mathrm{Ma}^{2 *}$
}

\footnotetext{
"Correspondence: kfmaxy@yeah.net

${ }^{2}$ Basic Experimental \& Teaching

Center, Henan University, Kaifeng 475000, China

Full list of author information is

available at the end of the article
}

\begin{abstract}
In this paper, common zeros of a family of accretive operators are investigated based on the Kirk-like proximal point algorithm. A strong convergence theorem is established in a reflexive Banach space.
\end{abstract}

Keywords: accretive operator; resolvent; strict convexness; zero

\section{Introduction}

In the real world, many important problems have reformulations which require finding common zero (fixed) points of nonlinear operators, for instance, image recovery, inverse problems, transportation problems and optimization problems. It is well known that the convex feasibility problem is a special case of the common zero (fixed) points of nonlinear operators. In 1971, Kirk [1] introduced a parallel iterative process for finding a family of nonexpansive mappings. Common fixed point theorems were established in a Banach space; for more details, see [1]. For studying zero points of monotone operators, the most well-known algorithm is the proximal point algorithm; see $[2,3]$ and the references therein. It is known that Rockfellar's proximal point algorithm is, in general, weak convergence; see [4] and the references therein.

Recently, many authors have been devoted to investigating the strong convergence of a proximal point algorithm. Strong convergence theorems for zero points of accretive operators were established; see, for example, [5-29] and the references therein.

In this paper, we are concerned with the problem of finding a common zero of a family of accretive operators based on the Kirk-like proximal point algorithm. A strong convergence theorem is established in a reflexive Banach space.

\section{Preliminaries}

Let $E$ be a Banach space with the dual $E^{*}$. Let $\langle\cdot, \cdot\rangle$ denote the pairing between $E$ and $E^{*}$. The normalized duality mapping $J: E \rightarrow 2^{E^{*}}$ is defined by

$$
J(x)=\left\{f \in E^{*}:\langle x, f\rangle=\|x\|^{2}=\|f\|^{2}\right\}, \quad \forall x \in E .
$$

Let $U_{E}=\{x \in E:\|x\|=1\}$. $E$ is said to be smooth or to have a Gâteaux differentiable norm if the $\operatorname{limit}_{t \rightarrow 0} \frac{\|x+t y\|-\|x\|}{t}$ exists for each $x, y \in U_{E}$. $E$ is said to have a uniformly Gâteaux differentiable norm if for each $y \in U_{E}$, the limit is attained uniformly for all $x \in U_{E}$. $E$ is 
said to be uniformly smooth or to have a uniformly Fréchet differentiable norm if the limit is attained uniformly for $x, y \in U_{E}$.

It is well known that (uniform) Fréchet differentiability of the norm of $E$ implies (uniform) Gâteaux differentiability of the norm of $E$. It is known that if the norm of $E$ is uniformly Gâteaux differentiable, then the duality mapping $j$ is single-valued and uniformly norm to weak* continuous on each bounded subset of $E$. In the sequel, we use $j$ to denote the single-valued normalized duality mapping.

A Banach space $E$ is said to be strictly convex if and only if

$$
\|x\|=\|y\|=\|(1-\lambda) x+\lambda y\|
$$

for $x, y \in E$, and $0<\lambda<1$ implies that $x=y$.

Recall that a closed convex subset $C$ of a Banach space $E$ is said to have a normal structure if for each bounded closed convex subset $K$ of $C$ which contains at least two points, there exists an element $x$ of $K$ which is not a diametral point of $K$, i.e., $\sup \{\|x-y\|: y \in$ $K\}<d(K)$, where $d(K)$ is the diameter of $K$.

Let $C$ be a nonempty closed convex subset of $E$. Let $T: C \rightarrow C$ be a mapping. In this paper, we use $F(T)$ to denote the set of fixed points of $T$. Recall that $T$ is said to be nonexpansive iff $\|T x-T y\| \leq\|x-y\|, \forall x, y \in C$. For the existence of fixed points of a nonexpansive mapping, we refer readers to [30].

Let $I$ denote the identity operator on $E$. An operator $A \subset E \times E$ with the domain $D(A)=$ $\{z \in E: A z \neq \emptyset\}$ and the range $R(A)=\bigcup\{A z: z \in D(A)\}$ is said to be accretive if for each $x_{i} \in$ $D(A)$ and $y_{i} \in A x_{i}, i=1,2$, there exists $j\left(x_{1}-x_{2}\right) \in J\left(x_{1}-x_{2}\right)$ such that $\left\langle y_{1}-y_{2}, j\left(x_{1}-x_{2}\right)\right\rangle \geq 0$. An accretive operator $A$ is said to be $m$-accretive if $R(I+r A)=E$ for all $r>0$. In this paper, we use $A^{-1}(0)$ to denote the set of zero points of $A$. For an accretive operator $A$, we can define a nonexpansive single-valued mapping $J_{r}: R(I+r A) \rightarrow D(A)$ by $J_{r}=(I+r A)^{-1}$ for each $r>0$, which is called the resolvent of $A$.

Next we give the following lemmas which play an important role in this article.

Lemma 2.1 [31] Let $E$ be a real Banach space and let $J$ be the normalized duality mapping. Then there exists $j(x+y) \in J(x+y)$ such that

$$
\|x+y\|^{2} \leq\|x\|^{2}+2\langle y, j(x+y)\rangle, \quad \forall x, y \in E .
$$

Lemma 2.2 [32] Let $C$ be a closed convex subset of a strictly convex Banach space E. Let $S: C \rightarrow C$ and $T: C \rightarrow c$ be two nonexpansive mappings. Suppose that $F(S) \cap F(T)$ is nonempty. Then the mapping $w S+(1-w) T$, where $s \in(0,1)$ is a real number, is well defined nonexpansive with $F(w S+(1-w) T)=F(S) \cap F(T)$.

Lemma 2.3 [33] Let E be a real reflexive Banach space with the uniformly Gâteaux differentiable norm and the normal structure, and let $C$ be a nonempty closed convex subset of E. Let $T: C \rightarrow C$ be a nonexpansive mapping with a fixed point. Let $\left\{x_{t}\right\}$ be a sequence generated by the following $x_{t}=t u+(1-t) T x_{t}$, where $t \in(0,1)$ and $u \in C$ is a fixed element. Then $\left\{x_{t}\right\}$ converges strongly as $t \rightarrow 0$ to a fixed point $x^{*}$ of $T$, which is the unique solution in $F(T)$ to the following variational inequality $\left\langle u-x^{*}, j\left(x^{*}-p\right)\right\rangle \geq 0, \forall p \in F(T)$. 
Lemma 2.4 [34] Let $\left\{a_{n}\right\},\left\{b_{n}\right\},\left\{c_{n}\right\}$ and $\left\{d_{n}\right\}$ be three nonnegative real sequences satisfying $a_{n+1} \leq\left(1-b_{n}\right) a_{n}+b_{n} c_{n}+d_{n}, \forall n \geq n_{0}$, where $n_{0}$ is some positive integer, $\left\{b_{n}\right\}$ is a number sequence in $(0,1)$ such that $\sum_{n=n_{0}}^{\infty} b_{n}=\infty,\left\{c_{n}\right\}$ is a number sequence such that $\limsup _{n \rightarrow \infty} c_{n} \leq 0$, and $\left\{d_{n}\right\}$ is a positive number sequence such that $\sum_{n=n_{0}}^{\infty} d_{n}<\infty$. Then $\lim _{n \rightarrow \infty} a_{n}=0$.

\section{Main results}

Theorem 3.1 Let E be a real reflexive, strictly convex Banach space with the uniformly Gâteaux differentiable norm. Let $N \geq 1$ be some positive integer. Let $A_{m}$ be an m-accretive operator in $E$ for each $m \in\{1,2, \ldots, N\}$. Assume that $C:=\bigcap_{m=1}^{N} \overline{D\left(A_{m}\right)}$ is convex and has the normal structure. Let $\left\{\alpha_{n}\right\}$ be a real number sequence in $(0,1)$ such that $\lim _{n \rightarrow \infty} \alpha_{n}=0$, $\sum_{n=1}^{\infty} \alpha_{n}=\infty$ and $\sum_{n=1}^{\infty}\left|\alpha_{n+1}-\alpha_{n}\right|<\infty$, let $\left\{\beta_{n, m}\right\}$ be a real number sequence in $(0,1)$ such that $\sum_{m=1}^{N} \beta_{n, m}=1, \lim _{n \rightarrow \infty} \beta_{n, m}=\beta_{m}$ and $\sum_{n=1}^{\infty}\left|\beta_{n+1, m}-\beta_{n, m}\right|<\infty$, let $\left\{r_{m}\right\}$ be a positive real number sequence, and let $\left\{e_{n, m}\right\}$ be a sequence in $E$ such that $\sum_{n=1}^{\infty}\left\|e_{n, m}\right\|<\infty$ for each $m \in\{1,2, \ldots, N\}$. Assume that $\bigcap_{m=1}^{N} A_{m}^{-1}(0)$ is not empty. Let $\left\{x_{n}\right\}$ be a sequence generated in the following manner:

$$
x_{1} \in C, \quad x_{n+1}=\alpha_{n} u+\left(1-\alpha_{n}\right) \sum_{m=1}^{N} \beta_{n, m} J_{r_{m}}\left(x_{n}+e_{n, m}\right), \quad \forall n \geq 1,
$$

where $u$ is a fixed element in $C$ and $J_{r_{m}}=\left(I+r_{m} A_{m}\right)^{-1}$. Then the sequence $\left\{x_{n}\right\}$ converges strongly to $\bar{x}$, which is the unique solution to the following variational inequality $\langle u-\bar{x}, j(p-$ $\bar{x})\rangle \leq 0, \forall p \in \bigcap_{m=1}^{N} A_{m}^{-1}(0)$.

Proof The proof is split into five steps.

Step 1. Show that $\left\{x_{n}\right\}$ is bounded.

Put $y_{n}=\sum_{m=1}^{N} \beta_{n, m} J_{r_{m}}\left(x_{n}+e_{n, m}\right)$. Fixing $p \in \bigcap_{m=1}^{N} A_{m}^{-1}(0)$, we find that

$$
\left\|y_{n}-p\right\| \leq \sum_{m=1}^{N} \beta_{n, m}\left\|J_{r_{m}}\left(x_{n}+e_{n, m}\right)-p\right\| \leq\left\|x_{n}-p\right\|+\sum_{m=1}^{N}\left\|e_{n, m}\right\| .
$$

It follows that

$$
\begin{aligned}
\left\|x_{n+1}-p\right\| & \leq \alpha_{n}\|u-p\|+\left(1-\alpha_{n}\right)\left\|y_{n}-p\right\| \\
& \leq \alpha_{n}\|u-p\|+\left(1-\alpha_{n}\right)\left\|x_{n}-p\right\|+\sum_{m=1}^{N}\left\|e_{n, m}\right\| \\
& \leq \max \left\{\|u-p\|,\left\|x_{n}-p\right\|\right\}+\sum_{m=1}^{N}\left\|e_{n, m}\right\| .
\end{aligned}
$$

By induction, we find that

$$
\left\|x_{n+1}-p\right\| \leq \max \left\{\|u-p\|,\left\|x_{1}-p\right\|\right\}+\sum_{i=1}^{\infty} \sum_{m=1}^{N}\left\|e_{i, m}\right\|<\infty .
$$

This proves Step 1. 
Step 2. Show that $\lim _{n \rightarrow \infty}\left\|x_{n+1}-x_{n}\right\|=0$.

Note that

$$
\begin{aligned}
y_{n}-y_{n-1}= & \sum_{m=1}^{N} \beta_{n, m}\left(J_{r_{m}}\left(x_{n}+e_{n, m}\right)-J_{r_{m}}\left(x_{n-1}+e_{n-1, m}\right)\right) \\
& +\sum_{m=1}^{N}\left(\beta_{n, m}-\beta_{n-1, m}\right) J_{r_{m}}\left(x_{n-1}+e_{n-1, m}\right) .
\end{aligned}
$$

It follows that

$$
\begin{aligned}
\left\|y_{n}-y_{n-1}\right\| \leq & \sum_{m=1}^{N} \beta_{n, m}\left\|J_{r_{m}}\left(x_{n}+e_{n, m}\right)-J_{r_{m}}\left(x_{n-1}+e_{n-1, m}\right)\right\| \\
& +\sum_{m=1}^{N}\left|\beta_{n, m}-\beta_{n-1, m}\right|\left\|J_{r_{m}}\left(x_{n-1}+e_{n-1, m}\right)\right\| \\
\leq & \left\|x_{n}-x_{n-1}\right\|+\sum_{m=1}^{N}\left\|e_{n, m}\right\|+\sum_{m=1}^{N}\left\|e_{n-1, m}\right\| \\
& +\sum_{m=1}^{N}\left|\beta_{n, m}-\beta_{n-1, m}\right|\left\|J_{r_{m}}\left(x_{n-1}+e_{n-1, m}\right)\right\| \\
\leq & \left\|x_{n}-x_{n-1}\right\|+M_{1} \sum_{m=1}^{N}\left|\beta_{n, m}-\beta_{n-1, m}\right|+\sum_{m=1}^{N}\left\|e_{n, m}\right\|+\sum_{m=1}^{N}\left\|e_{n-1, m}\right\|,
\end{aligned}
$$

where $M_{1}$ is an appropriate constant such that

$$
M_{1}=\max \left\{\sup _{n \geq 1}\left\|J_{r_{1}}\left(x_{n}+e_{n, 1}\right)\right\|, \sup _{n \geq 1}\left\|J_{r_{2}}\left(x_{n}+e_{n, 2}\right)\right\|, \ldots, \sup _{n \geq 1}\left\|J_{r_{N}}\left(x_{n}+e_{n, N}\right)\right\|\right\} .
$$

It follows that

$$
\begin{aligned}
\left\|x_{n+1}-x_{n}\right\| \leq & \left(1-\alpha_{n}\right)\left\|y_{n}-y_{n-1}\right\|+\left|\alpha_{n}-\alpha_{n-1}\right|\left\|u-y_{n-1}\right\| \\
\leq & \left(1-\alpha_{n}\right)\left\|x_{n}-x_{n-1}\right\|+M_{2}\left(\sum_{m=1}^{N}\left|\beta_{n, m}-\beta_{n-1, m}\right|+\left|\alpha_{n}-\alpha_{n-1}\right|\right) \\
& +\sum_{m=1}^{N}\left\|e_{n, m}\right\|+\sum_{m=1}^{N}\left\|e_{n-1, m}\right\|,
\end{aligned}
$$

where $M_{2}=\max \left\{M_{1}, \sup _{n \geq 1}\left\|u-y_{n}\right\|\right\}$. In view of Lemma 2.4, we conclude Step 2.

Step 3. Show that $\lim _{n \rightarrow \infty}\left\|T x_{n}-x_{n}\right\|=0$, where $T=\sum_{m=1}^{N} \beta_{m} J_{r_{m}}$. In light of Lemma 2.2, we see that $T$ is nonexpansive with $F(T)=\bigcap_{m=1}^{N} F\left(J_{r_{m}}\right)=\bigcap_{m=1}^{N} A_{m}^{-1}(0)$. Since

$$
\begin{aligned}
\left\|y_{n}-T x_{n}\right\| \leq & \left\|\sum_{m=1}^{N} \beta_{n, m} J_{r_{m}}\left(x_{n}+e_{n, m}\right)-\sum_{m=1}^{N} \beta_{m} J_{r_{m}}\left(x_{n}+e_{n, m}\right)\right\| \\
& +\left\|\sum_{m=1}^{N} \beta_{m} J_{r_{m}}\left(x_{n}+e_{n, m}\right)-\sum_{m=1}^{N} \beta_{m} J_{r_{m}} x_{n}\right\| \\
\leq & \sum_{m=1}^{N}\left|\beta_{n, m}-\beta_{m}\right|\left\|J_{r_{m}}\left(x_{n}+e_{n, m}\right)\right\|+\sum_{m=1}^{N}\left\|e_{n, m}\right\|,
\end{aligned}
$$


we find from the restrictions imposed on the control sequences that $\lim _{n \rightarrow \infty}\left\|T x_{n}-y_{n}\right\|=$ 0 . Since

$$
\begin{aligned}
\left\|T x_{n}-x_{n}\right\| & \leq\left\|x_{n}-x_{n+1}\right\|+\left\|x_{n+1}-T x_{n}\right\| \\
& \leq\left\|x_{n}-x_{n+1}\right\|+\alpha_{n}\left\|u-J x_{n}\right\|+\left(1-\alpha_{n}\right)\left\|y_{n}-T x_{n}\right\|,
\end{aligned}
$$

we conclude Step 3.

Step 4. Show that $\lim \sup _{n \rightarrow \infty}\left\langle u-\bar{x}, j\left(x_{n}-\bar{x}\right)\right\rangle \leq 0$, where $\bar{x}=\lim _{t \rightarrow 0} x_{t}$, and $x_{t}$ solves the fixed point equation

$$
x_{t}=t u+(1-t) T x_{t}, \quad \forall t \in(0,1) .
$$

It follows that

$$
\begin{aligned}
\left\|x_{t}-x_{n}\right\|^{2}= & t\left\langle u-x_{n}, j\left(x_{t}-x_{n}\right)\right\rangle+(1-t)\left\langle T x_{t}-x_{n}, j\left(x_{t}-x_{n}\right)\right\rangle \\
= & t\left\langle u-x_{t}, j\left(x_{t}-x_{n}\right)\right\rangle+t\left\langle x_{t}-x_{n}, j\left(x_{t}-x_{n}\right)\right\rangle \\
& +(1-t)\left\langle T x_{t}-T x_{n}, j\left(x_{t}-x_{n}\right)\right\rangle+(1-t)\left\langle T x_{n}-x_{n}, j\left(x_{t}-x_{n}\right)\right\rangle \\
\leq & t\left\langle u-x_{t}, j\left(x_{t}-x_{n}\right)\right\rangle+\left\|x_{t}-x_{n}\right\|^{2}+\left\|T x_{n}-x_{n}\right\|\left\|x_{t}-x_{n}\right\|, \quad \forall t \in(0,1) .
\end{aligned}
$$

This implies that

$$
\left\langle x_{t}-u, j\left(x_{t}-x_{n}\right)\right\rangle \leq \frac{1}{t}\left\|T x_{n}-x_{n}\right\|\left\|x_{t}-x_{n}\right\|, \quad \forall t \in(0,1) .
$$

Since $\lim _{n \rightarrow \infty}\left\|T x_{n}-x_{n}\right\|=0$, we find that $\limsup _{n \rightarrow \infty}\left\langle x_{t}-u, j\left(x_{t}-x_{n}\right)\right\rangle \leq 0$. In view of the fact that $j$ is strong to weak* uniformly continuous on bounded subsets of $E$, we find that

$$
\begin{aligned}
\mid\langle u- & \left.\bar{x}, j\left(x_{n}-\bar{x}\right)\right\rangle-\left\langle x_{t}-u, j\left(x_{t}-x_{n}\right)\right\rangle \mid \\
\leq & \left|\left\langle u-\bar{x}, j\left(x_{n}-\bar{x}\right)\right\rangle-\left\langle u-\bar{x}, j\left(x_{n}-x_{t}\right)\right\rangle\right| \\
& \quad+\left|\left\langle u-\bar{x}, j\left(x_{n}-x_{t}\right)\right\rangle-\left\langle x_{t}-u, j\left(x_{t}-x_{n}\right)\right\rangle\right| \\
\leq & \left|\left\langle u-\bar{x}, j\left(x_{n}-\bar{x}\right)-j\left(x_{n}-x_{t}\right)\right\rangle\right|+\left|\left\langle u-\bar{x}+x_{t}-u, j\left(x_{n}-x_{t}\right)\right\rangle\right| \\
\leq & \|u-\bar{x}\|\left\|j\left(x_{n}-\bar{x}\right)-j\left(x_{n}-x_{t}\right)\right\|+\left\|x_{t}-\bar{x}\right\|\left\|x_{n}-x_{t}\right\| .
\end{aligned}
$$

Since $x_{t} \rightarrow \bar{x}$, as $t \rightarrow 0$, we have

$$
\lim _{t \rightarrow 0}\left|\left\langle x_{t}-u, j\left(x_{t}-x_{n}\right)\right\rangle-\left\langle u-\bar{x}, j\left(x_{n}-\bar{x}\right)\right\rangle\right|=0
$$

For $\epsilon>0$, there exists $\delta>0$ such that $\forall t \in(0, \delta)$, we have

$$
\left\langle u-\bar{x}, j\left(x_{n}-\bar{x}\right)\right\rangle \leq\left\langle x_{t}-u, j\left(x_{t}-x_{n}\right)\right\rangle+\epsilon .
$$

This implies that

$$
\limsup _{n \rightarrow \infty}\left\langle u-\bar{x}, j\left(x_{n}-\bar{x}\right)\right\rangle \leq \limsup _{n \rightarrow \infty}\left\langle x_{t}-u, j\left(x_{t}-x_{n}\right)\right\rangle+\epsilon .
$$


Since $\epsilon$ is arbitrarily chosen, we find that $\lim _{\sup _{n \rightarrow \infty}}\left\langle u-\bar{x}, j\left(x_{n}-\bar{x}\right)\right\rangle \leq 0$. This implies that $\limsup _{n \rightarrow \infty}\left\langle u-\bar{x}, j\left(x_{n+1}-\bar{x}\right)\right\rangle \leq 0$. This proves Step 4 .

Step 5. Show that $x_{n} \rightarrow \bar{x}$ as $n \rightarrow \infty$.

Using Lemma 2.1, we find that

$$
\begin{aligned}
\left\|x_{n+1}-\bar{x}\right\|^{2} & =\left\|\alpha_{n}(u-\bar{x})+\left(1-\alpha_{n}\right)\left(\sum_{m=1}^{N} \beta_{n, m}\left(J_{r_{m}}\left(x_{n}+e_{n, m}\right)-\bar{x}\right)\right)\right\|^{2} \\
& \leq\left(1-\alpha_{n}\right)^{2}\left\|\sum_{m=1}^{N} \beta_{n, m}\left(J_{r_{m}}\left(x_{n}+e_{n, m}\right)-\bar{x}\right)\right\|^{2}+2 \alpha_{n}\left\langle u-\bar{x}, j\left(x_{n+1}-\bar{x}\right)\right\rangle \\
& \leq\left(1-\alpha_{n}\right)^{2} \sum_{m=1}^{N} \beta_{n, m}\left\|x_{n}+e_{n, m}-\bar{x}\right\|^{2}+2 \alpha_{n}\left\langle u-\bar{x}, j\left(x_{n+1}-\bar{x}\right)\right\rangle \\
& \leq\left(1-\alpha_{n}\right)\left\|x_{n}-\bar{x}\right\|^{2}+\lambda_{n}+2 \alpha_{n}\left\langle u-\bar{x}, j\left(x_{n+1}-\bar{x}\right)\right\rangle,
\end{aligned}
$$

where $\lambda_{n}=\sum_{m=1}^{N}\left(\left\|e_{n, m}\right\|^{2}+2\left\|e_{n, m}\right\|\left\|x_{n}-\bar{x}\right\|\right)$. We, therefore, find that $\sum_{n=1}^{\infty} \lambda_{n}<\infty$. From Lemma 2.4, we find the desired conclusion. This proves the proof.

Remark 3.2 Theorem 3.1 is still valid in the framework of the space which is uniformly convex and the norm is uniformly Gâteaux differentiable.

\section{Applications}

In this section, we consider an application of Theorem 3.1. Let $A: C \rightarrow E^{*}$ be a singlevalued monotone operator which is hemicontinuous; that is, continuous along each line segment in $C$ with respect to the weak* topology of $E^{*}$. Consider the following variational inequality:

find $x \in C$ such that $\langle y-x, A x\rangle \geq 0, \quad \forall y \in C$.

The solution set of the variational inequality is denoted by $V I(C, A)$. Recall that the normal cone $N_{C}(x)$ for $C$ at a point $x \in C$ is defined by

$$
N_{C}(x)=\left\{x^{*} \in E^{*}:\left\langle y-x, x^{*}\right\rangle \leq 0, \forall y \in C\right\} .
$$

Now, we are in a position to give the result on the variational inequality.

Theorem 4.1 Let E be a real reflexive, strictly convex Banach space with the uniformly Gâteaux differentiable norm. Let $N \geq 1$ be some positive integer and let $C$ be a nonempty closed and convex subset of E. Let $A_{m}: C \rightarrow E^{*}$ be a single-valued, monotone and hemicontinuous operator. Assume that $\bigcap_{m=1}^{N} V I\left(C, A_{m}\right)$ is not empty and $C$ has the normal structure. Let $\left\{\alpha_{n}\right\}$ be a real number sequence in $(0,1)$ such that $\lim _{n \rightarrow \infty} \alpha_{n}=0, \sum_{n=1}^{\infty} \alpha_{n}=\infty$ and $\sum_{n=1}^{\infty}\left|\alpha_{n+1}-\alpha_{n}\right|<\infty$, let $\left\{\beta_{n, m}\right\}$ be a real number sequence in $(0,1)$ such that $\sum_{m=1}^{N} \beta_{n, m}=1$, $\lim _{n \rightarrow \infty} \beta_{n, m}=\beta_{m}$ and $\sum_{n=1}^{\infty}\left|\beta_{n+1, m}-\beta_{n, m}\right|<\infty$, let $\left\{r_{m}\right\}$ be a positive real number sequence for each $m \in\{1,2, \ldots, N\}$. Assume that $\left\{x_{n}\right\}$ is a sequence generated in the following manner:

$$
x_{1} \in C, \quad x_{n+1}=\alpha_{n} u+\left(1-\alpha_{n}\right) \sum_{m=1}^{N} \beta_{n, m} V I\left(C, A_{m}+\frac{1}{r_{m}}\left(I-x_{n}\right)\right), \quad \forall n \geq 1,
$$


where $u$ is a fixed element in $C$. Then the sequence $\left\{x_{n}\right\}$ converges strongly to $\bar{x}$, which is the unique solution to the following variational inequality $\langle u-\bar{x}, j(p-\bar{x})\rangle \leq 0, \forall p \in$ $\bigcap_{m=1}^{N} \operatorname{VI}\left(C, A_{m}\right)$.

Proof First, we define a mapping $T_{m} \subset E \times E^{*}$ by

$$
T_{m} x= \begin{cases}A_{m} x+N_{C} x, & x \in C, \\ \emptyset, & x \notin C .\end{cases}
$$

From Rockafellar [33], we find that $T_{m}$ is maximal monotone and $T_{m}^{-1}(0)=V I\left(C, A_{m}\right)$. For each $r_{m}>0$ and $x_{n} \in E$, we see that there exists a unique $x_{r_{m}} \in D\left(T_{m}\right)$ such that $x_{n} \in$ $x_{r_{m}}+r_{m} T_{m}\left(x_{r_{m}}\right)$, where $x_{r_{m}}=\left(I+r_{m} T_{m}\right)^{-1} x_{n}$. Notice that

$$
y_{n, m}=V I\left(C, A_{m}+\frac{1}{r_{m}}\left(I-x_{n}\right)\right) \text {, }
$$

which is equivalent to

$$
\left\langle y-y_{n, m}, A_{m} y_{n, m}+\frac{1}{r_{m}}\left(y_{n, m}-x_{n}\right)\right\rangle \geq 0, \quad \forall y \in C,
$$

that is, $-A_{m} y_{n, m}+\frac{1}{r_{m}}\left(x_{n}-y_{n, m}\right) \in N_{C}\left(y_{n, m}\right)$. This implies that $y_{n, m}=\left(I+r_{m} T_{m}\right)^{-1} x_{n}$. In light of Theorem 3.1, we draw the desired conclusion immediately.

\section{Competing interests}

The authors declare that they have no competing interests.

\section{Authors' contributions}

Both authors contributed equally to this manuscript. Both authors read and approved the final manuscript.

\section{Author details}

${ }^{1}$ School of Mathematics and Information Science, North China University of Water Resources and Electric Power,

Zhengzhou, 450011, China. ${ }^{2}$ Basic Experimental \& Teaching Center, Henan University, Kaifeng, 475000, China.

\section{Acknowledgements}

The authors are grateful to the reviewers for their suggestions which improved the contents of the article.

Received: 1 January 2014 Accepted: 25 March 2014 Published: 06 May 2014

\section{References}

1. Kirk, WA: On successive approximations for nonexpansive mappings in Banach spaces. Glasg. Math. J. 12, 6-9 (1971)

2. Rockfellar, RT: Augmented Lagrangians and applications of the proximal point algorithm in convex programming. Math. Oper. Res. 1, 97-116 (1976)

3. Rockfellar, RT: Monotone operators and proximal point algorithm. SIAM J. Control Optim. 14, 877-898 (1976)

4. Güler, O: On the convergence of the proximal point algorithm for convex minimization. SIAM J. Control Optim. 29, 403-419 (1991)

5. Cho, SY, Kang, SM: Approximation of fixed points of pseudocontraction semigroups based on a viscosity iterative process. Appl. Math. Lett. 24, 224-228 (2011)

6. Qin, X, Su, Y: Approximation of a zero point of accretive operator in Banach spaces. J. Math. Anal. Appl. 329, 415-424 (2007)

7. Jung, JS: Some results on Rockafellar-type iterative algorithms for zeros of accretive operators. J. Inequal. Appl. 2013, Article ID 255 (2013)

8. Kim, JK: Convergence of Ishikawa iterative sequences for accretive Lipschitzian mappings in Banach spaces. Taiwan. J. Math. 10, 553-561 (2006)

9. Qin, X, Kang, SM, Cho, YJ: Approximating zeros of monotone operators by proximal point algorithms. J. Glob. Optim. 46, 75-87 (2010)

10. Wu, C, LV, S: Bregman projection methods for zeros of monotone operators. J. Fixed Point Theory 2013, Article ID 7 (2013) 
11. Wu, C: Convergence of algorithms for an infinite family nonexpansive mappings and relaxed cocoercive mappings in Hilbert spaces. Adv. Fixed Point Theory 4, 125-139 (2014)

12. Cho, SY, Qin, X, Kang, SM: Iterative processes for common fixed points of two different families of mappings with applications. J. Glob. Optim. 57, 1429-1446 (2013)

13. Yang, S: Zero theorems of accretive operators in reflexive Banach spaces. J. Nonlinear Funct. Anal. 2013, Article ID 2 (2013)

14. Song, J, Chen, M: A modified Mann iteration for zero points of accretive operators. Fixed Point Theory Appl. 2013, Article ID 347 (2013)

15. Qin, X, Agarwal, RP: Shrinking projection methods for a pair of asymptotically quasi- $\boldsymbol{\phi}$-nonexpansive mappings. Numer. Funct. Anal. Optim. 31, 1072-1089 (2010)

16. Qin, $X, C h o, S Y$, Wang, L: A regularization method for treating zero points of the sum of two monotone operators. Fixed Point Theory Appl. 2014, Article ID 75 (2014)

17. Hao, Y: Zero theorems of accretive operators. Bull. Malays. Math. Soc. 34, 103-112 (2011)

18. $\mathrm{Hu}, \mathrm{L}, \mathrm{Liu}, \mathrm{L}: \mathrm{A}$ new iterative algorithm for common solutions of a finite family of accretive operators. Nonlinear Anal. 70, 344-2351 (2009)

19. Cho, SY, Kang, SM: Zero point theorems for $m$-accretive operators in a Banach space. Fixed Point Theory 13, 49-58 (2012)

20. Cho, SY, Li, W, Kang, SM: Convergence analysis of an iterative algorithm for monotone operators. J. Inequal. Appl. 2013, Article ID 199 (2013)

21. Cho, SY, Qin, X, Wang, L: Strong convergence of a splitting algorithm for treating monotone operators. Fixed Point Theory Appl. 2014, Article ID 94 (2014)

22. Reich, S: Strong convergence theorems for resolvents of accretive operators in Banach spaces. J. Math. Anal. Appl. 75 287-292 (1980)

23. Qing, Y, Cho, SY: Proximal point algorithms for zero points of nonlinear operators. Fixed Point Theory Appl. 2014, Article ID 42 (2014)

24. Rodjanadid, B, Sompong, S: A new iterative method for solving a system of generalized equilibrium problems, generalized mixed equilibrium problems and common fixed point problems in Hilbert spaces. Adv. Fixed Point Theory 3, 675-705 (2013)

25. Qing, Y, Cho, SY, Qin, X: Convergence of iterative sequences for common zero points of a family of $m$-accretive mappings in Banach spaces. Fixed Point Theory Appl. 2011, Article ID 216173 (2011)

26. Takahashi, W: Viscosity approximation methods for resolvents of accretive operators in Banach spaces. J. Fixed Point Theory Appl. 1, 135-147 (2007)

27. Cho, SY, Qin, X: On the strong convergence of an iterative process for asymptotically strict pseudocontractions and equilibrium problems. Appl. Math. Comput. 235, 430-438 (2014)

28. Zegeye, $\mathrm{H}$, Shahzad, N: Strong convergence theorem for a common point of solution of variational inequality and fixed point problem. Adv. Fixed Point Theory 2, 374-397 (2012)

29. Cho, SY, Kang, SM: Approximation of common solutions of variational inequalities via strict pseudocontractions. Acta Math. Sci. 32, 1607-1618 (2011)

30. Kirk, WA: A fixed point theorem for mappings which do not increase distances. Am. Math. Mon. 72, 1004-1006 (1965)

31. Chang, SS: Some problems and results in the study of nonlinear analysis. Nonlinear Anal. 30, 4197-4208 (1997)

32. Bruck, RE: Properties of fixed-point sets of nonexpansive mappings in Banach spaces. Trans. Am. Math. Soc. 179, 251-262 (1973)

33. Qin, X, Cho, SY, Wang, L: Iterative algorithms with errors for zero points of $m$-accretive operators. Fixed Point Theory Appl. 2013, Article ID 148 (2013)

34. Liu, L: Ishikawa and Mann iterative process with errors for nonlinear strongly accretive mappings in Banach spaces. J. Math. Anal. Appl. 194, 114-125 (1995)

10.1186/1687-1812-2014-105

Cite this article as: Huang and Ma: Strong convergence theorems for common zeros of a family of accretive operators. Fixed Point Theory and Applications 2014, 2014:105

\section{Submit your manuscript to a SpringerOpen ${ }^{\circ}$ journal and benefit from:}

- Convenient online submission

Rigorous peer review

- Immediate publication on acceptance

Open access: articles freely available online

- High visibility within the field

- Retaining the copyright to your article

Submit your next manuscript at $>$ springeropen.com 